\title{
Public opinion of a stroke clinical trial using exception from informed consent
}

\author{
Joshua N. Goldstein • Janice A. Espinola • \\ Jonathan Fisher • Daniel J. Pallin • \\ Carlos A. Camargo Jr.
}

Received: 2 July 2010 /Accepted: 5 September 2010 /Published online: 10 November 2010

(C) The Author(s) 2010. This article is published with open access at Springerlink.com

\begin{abstract}
Background Acute stroke is a leading cause of morbidity and mortality. Clinical trials in stroke are challenging because victims often do not have the capacity to provide informed consent, excluding those patients most likely to benefit from the research.

Aim We evaluated patient willingness to participate in a hypothetical acute stroke trial using an exception from informed consent.

Methods Consecutive patients presenting to four emergency departments (EDs) underwent structured interviews regarding a hypothetical stroke trial using an exception from informed consent.
\end{abstract}

\footnotetext{
D. J. Pallin

Department of Emergency Medicine,

Brigham \& Women's Hospital,

Boston, MA, USA

J. N. Goldstein $(\varangle) \cdot$ J. A. Espinola $\cdot$ C. A. Camargo Jr.

Department of Emergency Medicine,

Massachusetts General Hospital,

Zero Emerson Place, Suite 3B,

Boston, MA 02114, USA

e-mail: jgoldstein@partners.org

J. Fisher

Department of Emergency Medicine,

Beth Israel Deaconess Medical Center,

Boston, MA, USA

D. J. Pallin

Department of Emergency Medicine, Children's Hospital Boston,

Boston, MA, USA

J. N. Goldstein · J. Fisher - D. J. Pallin - C. A. Camargo Jr. Division of Emergency Medicine, Harvard Medical School, Boston, MA, USA
}

Results Of 461 (72\% of eligible) participants, 55\% (95\% CI, $50 \%-59 \%$ ) were willing to be enrolled in the hypothetical study without giving informed consent. After multivariable analysis, independent predictors of willingness to enroll included Catholic religion (OR 1.57, 95\% CI 1.17-2.10) and belief that current therapy offers a $>50 \%$ chance of full recovery (OR 1.29, 95\% CI 1.05-1.57). There was no difference between the proportion willing to enroll in a cardiac arrest study vs. a stroke study ( $55 \%$ vs. $55 \%, \mathrm{p}=0.83$ ) Conclusions Fifty-five percent of ED patients would be willing to be enrolled in a stroke trial using exception from informed consent.

Keywords Informed consent $\cdot$ Public opinion · Stroke

\section{Introduction}

Acute stroke is a leading cause of morbidity and mortality, and few interventions have proven to improve outcome [1]. Altered mental status among stroke victims limits their ability to give informed consent, which excludes those patients most likely to benefit, skewing the study population towards those with the least severe strokes [2-4]. Therefore, some have advocated for use of an exception from the standard informed consent procedure [5,6]. While research using this exception is allowable under federal regulations, the process is both logistically and ethically complex, and typically applied to a narrow range of diseases.

When stroke survivors and caregivers are involved in stroke trial development, they have advocated for exception from consent [7]. The only study examining patient opinion of such an exception interviewed patients after their stroke had occurred, finding that $92 \%$ would be willing to participate [8]. These patients may be more aware of the 
long-term morbidity of stroke and the limitations of current therapies, and thus be more supportive of such research than the general public.

To investigate public opinion, we interviewed a consecutive cohort of patients presenting to the emergency department (ED) for a variety of conditions [9]. Since it is impossible to discuss this issue with actual patients at the time of their stroke, we interviewed patients in the ED who would be more aware of the need for emergency evaluation and treatment, but be cognitively intact. The primary analysis examined the effect of an educational intervention on patient opinion of exception from consent in general and was published previously [9]. Here, we report a secondary analysis examining independent predictors of participants' willingness to participate in a stroke trial in particular.

\section{Methods}

We described the study design previously, including the full questionnaire text [9]. Briefly, consecutive patients presenting to four EDs during selected 24-h periods were approached. Adults (aged >18) who were awake and responsive were eligible for enrollment. Subjects were excluded for medical instability, mental illness, intoxication, complaint of sexual assault, or if they were prisoners. The original study tested the hypothesis that an educational intervention would increase willingness to participate; subjects were randomized to receive the control survey or one with a paragraph discussing the ethical/legal requirements involved in using exception from informed consent [9]. The hypothetical stroke study is shown in Fig. 1; subjects were also asked about a hypothetical cardiac arrest study.

For analysis of the dichotomous variable "willing to enroll," we collapsed answers from a 5-point Likert scale into "agree" (the responses Strongly Agree and Agree), and "do not agree" (Neutral, Disagree, and Strongly Disagree). We performed multivariable logistic regression to determine predictors of willingness to participate, with predictor variables chosen a priori based upon previously published data or suspected influence on willingness to participate in research. The model included a term for site, to account for within-ED clustering. We used Stata 9.0 (StataCorp, College Station, TX) for analysis. We also collected qualitative data using open-ended questions. The study was approved by the Institutional Review Boards of all participating sites.

\section{Results}

Of 1,080 patients presenting to the four EDs during the study period, 640 were eligible, 473 participated, and $461(72 \%)$ answered all questions including opinion on the hypothetical stroke study (Table 1). Fifty-five percent would be willing to participate in the hypothetical stroke study, a similar proportion to that willing to participate in a hypothetical cardiac arrest study (also $55 \%, \mathrm{p}=0.83$ ). Univariate analysis identified no significant predictors of willingness to participate in the hypothetical stroke study. Multivariate analysis identified the following independent predictors of willingness to be enrolled: male sex, Catholic religion, and belief that current therapy offers $>50 \%$ chance of full recovery (Table 2).

Qualitative comments were provided by $37(15 \%)$ of those who were willing to participate, and by $50(24 \%)$ who were neutral or unwilling. The most common statement was the belief that a surrogate is always immediately available $(n=15)$. Other common statements included that the risks were too high $(n=10)$; that the research should proceed in case it might help $(\mathrm{n}=6)$; and that patients should only be enrolled if it were already known that the treatment would help $(n=4)$.

Fig. 1 Case scenario

Case Scenario: When a person has an acute stroke, they can suddenly lose control of their arms, legs, or ability to speak with or understand other people. There is a new treatment for this but it must be given immediately. Doctors think that this medication will increase the chance of recovering brain function in some patients, but are worried that it may increase the risk of bleeding in the brain. They need to do a study to find out if this treatment helps people; however, people with a stroke may not be able to give their consent for such a study.

Question: If I had an acute stroke and could no longer understand or provide consent, I would be willing to be entered into this study without giving consent.
1. Strongly disagree
3. Neutral
4. Agree
2. Disagree
5. Strongly agree 
Table 1 Demographic

characteristics, by willingness to participate in a hypothetical stroke trial

*IQR, Interquartile range

\begin{tabular}{|c|c|c|c|c|}
\hline & Disagree & Neutral & Agree & $P$ value \\
\hline Overall $(n=461)$ & $34 \%$ & $11 \%$ & $55 \%$ & \\
\hline Age, median (IQR) & $46(27-63)$ & $43(29-59)$ & $47(31-59)$ & 0.95 \\
\hline Income in $\$ 1,000 \mathrm{~s}$, median (IQR) & $59(47-79)$ & $59(47-68)$ & $66(47-79)$ & 0.74 \\
\hline Sex & & & & 0.61 \\
\hline Male $(n=214)$ & $31 \%$ & $9 \%$ & $60 \%$ & \\
\hline Female $(n=241)$ & $36 \%$ & $12 \%$ & $51 \%$ & \\
\hline Race & & & & 0.69 \\
\hline White $(\mathrm{n}=290)$ & $33 \%$ & $11 \%$ & $57 \%$ & \\
\hline Black $(\mathrm{n}=80)$ & $38 \%$ & $11 \%$ & $51 \%$ & \\
\hline Other $(\mathrm{n}=77)$ & $36 \%$ & $14 \%$ & $49 \%$ & \\
\hline Ethnicity & & & & 0.25 \\
\hline Non-Hispanic $(\mathrm{n}=400)$ & $34 \%$ & $11 \%$ & $55 \%$ & \\
\hline Hispanic $(\mathrm{n}=18)$ & $32 \%$ & $12 \%$ & $56 \%$ & \\
\hline Religion & & & & 0.30 \\
\hline Protestant $(n=100)$ & $36 \%$ & $15 \%$ & $49 \%$ & \\
\hline Catholic $(\mathrm{n}=192)$ & $34 \%$ & $7 \%$ & $59 \%$ & \\
\hline Other $(\mathrm{n}=85)$ & $28 \%$ & $20 \%$ & $52 \%$ & \\
\hline None $(\mathrm{n}=81)$ & $37 \%$ & $6 \%$ & $57 \%$ & \\
\hline Strong connection to religion & & & & 0.52 \\
\hline No $(n=230)$ & $33 \%$ & $10 \%$ & $56 \%$ & \\
\hline Yes $(n=148)$ & $34 \%$ & $14 \%$ & $51 \%$ & \\
\hline Education & & & & 0.62 \\
\hline$<8$ th grade $(n=22)$ & $23 \%$ & $14 \%$ & $64 \%$ & \\
\hline$<12$ th grade $(n=23)$ & $30 \%$ & $9 \%$ & $61 \%$ & \\
\hline High school $(\mathrm{n}=132)$ & $34 \%$ & $12 \%$ & $54 \%$ & \\
\hline Some college $(n=109)$ & $39 \%$ & $7 \%$ & $53 \%$ & \\
\hline College $(n=113)$ & $34 \%$ & $13 \%$ & $53 \%$ & \\
\hline Post grad. $(n=62)$ & $32 \%$ & $11 \%$ & $56 \%$ & \\
\hline Insurance & & & & 0.84 \\
\hline Private $(n=262)$ & $33 \%$ & $11 \%$ & $56 \%$ & \\
\hline Medicare $(\mathrm{n}=18)$ & $17 \%$ & $11 \%$ & $72 \%$ & \\
\hline Medicaid $(n=62)$ & $35 \%$ & $11 \%$ & $53 \%$ & \\
\hline None $(n=24)$ & $33 \%$ & $4 \%$ & $63 \%$ & \\
\hline Other $(n=88)$ & $39 \%$ & $11 \%$ & $50 \%$ & \\
\hline \multicolumn{5}{|c|}{ "What do you think your chance of recovering ... is, based on current therapies?" } \\
\hline$<5 \%(\mathrm{n}=27)$ & $41 \%$ & $4 \%$ & $55 \%$ & \\
\hline $5-50 \%(n=94)$ & $38 \%$ & $10 \%$ & $52 \%$ & \\
\hline $50 / 50(n=176)$ & $33 \%$ & $14 \%$ & $53 \%$ & \\
\hline$>50 \%(\mathrm{n}=120)$ & $32 \%$ & $12 \%$ & $57 \%$ & \\
\hline$>95 \%(\mathrm{n}=30)$ & $20 \%$ & $7 \%$ & $73 \%$ & 0.30 \\
\hline Educational intervention & & & & 1.0 \\
\hline No $(n=233)$ & $34 \%$ & $11 \%$ & $55 \%$ & \\
\hline Yes $(n=228)$ & $35 \%$ & $11 \%$ & $54 \%$ & \\
\hline
\end{tabular}

\section{Discussion}

We found that $55 \%$ of potential subjects would be willing to participate in a stroke trial without informed consent,
$11 \%$ were neutral, and $34 \%$ would refuse. Prior research has shown $34-84 \%$ of respondents to be willing to participate in other studies such as cardiac arrest without informed consent [10]. 
Table 2 Multivariable

analysis of clinical features associated with willingness to participate in a hypothetical stroke trial

\begin{tabular}{|c|c|}
\hline Clinical factor & Odds ratio $(95 \% \mathrm{CI})$ \\
\hline Age per decade & $1.0(0.8-1.2)$ \\
\hline Household income (per US\$10,000) & $1.0(0.9-1.1)$ \\
\hline Female sex & $0.8(0.7-0.9)$ \\
\hline \multicolumn{2}{|l|}{ Race: } \\
\hline White & Referent \\
\hline Black & $1.0(0.7-1.6)$ \\
\hline Other & $0.7(0.5-1.0)$ \\
\hline Hispanic ethnicity & $1.2(0.5-2.7)$ \\
\hline \multicolumn{2}{|l|}{ Education: } \\
\hline$<8$ th grade & Referent \\
\hline Some high school & $0.9(0.4-2.0)$ \\
\hline High school & $0.8(0.4-1.4)$ \\
\hline Some college & $0.8(0.4-1.3)$ \\
\hline College & $0.8(0.4-1.7)$ \\
\hline Post graduate & $1.1(0.4-3.0)$ \\
\hline \multicolumn{2}{|l|}{ Religion: } \\
\hline Protestant & Referent \\
\hline Catholic & $1.6(1.2-2.1)$ \\
\hline Other & $1.1(0.6-2.0)$ \\
\hline None & $1.4(0.7-2.8)$ \\
\hline \multicolumn{2}{|l|}{ Insurance: } \\
\hline Private & Referent \\
\hline Medicare & $2.1(0.7-6.3)$ \\
\hline Medicaid & $0.9(0.6-1.3)$ \\
\hline None & $1.3(0.3-5.9)$ \\
\hline Other & $0.7(0.2-2.7)$ \\
\hline Belief that current therapies offer a $>50 \%$ chance of full recovery & $1.3(1.1-1.6)$ \\
\hline Educational intervention & $1.0(0.7-1.6)$ \\
\hline
\end{tabular}

Multivariable analysis revealed that patients with a more optimistic view of the benefits of current therapies were more willing to participate. It may be that those with more positive opinions of clinical care also have more faith in the ethical management of clinical trials or a greater belief that research carries clinical benefit for the participants. We also noted an effect of sex and religious affiliation on willingness to enroll; the reason for this is unclear. Future studies will be necessary to clarify whether these relationships are artifacts of multiple hypothesis testing, or whether there is a reason that males and Catholics are more willing to participate in research without consent.

Our study is limited by the fact that not all eligible subjects completed the survey; a response rate over $80 \%$ would be preferred. Also, by excluding the most severely ill patients, we may have missed those most likely to be enrolled in studies using an exception from informed consent and whose opinions are most critical. Unfortunately, while such patients who survive cognitively intact could be interviewed after their clinical course has stabilized, such interviews would select for those who benefited most from standard therapy, and decision-making at the time of the stroke may be quite different from that made long afterwards. Finally, healthy people at risk for stroke could be interviewed to avoid any biases from being in the emergency department at the time of the survey. However, patients' opinions of research (and medical care) may be quite different when in close spatial and psychological proximity to a true medical emergency, and so such surveys may introduce a separate set of biases.

These data add to the growing body of evidence for patients' support of emergency research without informed consent. Clinical trials in stroke have not traditionally been considered candidates for exception from consent; however, our data support the concept that within the context of current federal regulations (including factors such as clinical equipoise, ethics board approval, and absence of a surrogate), the majority of patients would be willing to participate in clinical trials of novel stroke therapies without consent. 
Acknowledgments Supported by grants from the Esther B. Kahn Research Award, Brigham \& Women's Hospital, and NINDS (NS059774). The authors report no relevant conflicts of interest.

Open Access This article is distributed under the terms of the Creative Commons Attribution Noncommercial License which permits any noncommercial use, distribution, and reproduction in any medium, provided the original author(s) and source are credited.

\section{References}

1. Adams HP Jr, del Zoppo G, Alberts MJ, Bhatt DL, Brass L, Furlan A, Grubb RL, Higashida RT, Jauch EC, Kidwell C, Lyden PD, Morgenstern LB, Qureshi AI, Rosenwasser RH, Scott PA, Wijdicks EF (2007) Guidelines for the early management of adults with ischemic stroke: a guideline from the American Heart Association/American Stroke Association Stroke Council, Clinical Cardiology Council, Cardiovascular Radiology and Intervention Council, and the Atherosclerotic Peripheral Vascular Disease and Quality of Care Outcomes in Research Interdisciplinary Working Groups: the American Academy of Neurology affirms the value of this guideline as an educational tool for neurologists. Stroke $38: 1655-1711$

2. Tu JV, Willison DJ, Silver FL, Fang J, Richards JA, Laupacis A, Kapral MK (2004) Impracticability of informed consent in the registry of the Canadian Stroke Network. N Engl J Med 350:1414-1421
3. Chen DT, Case LD, Brott TG, Brown RD Jr, Silliman SL, Meschia JF, Worrall BB (2008) Impact of restricting enrollment in stroke genetics research to adults able to provide informed consent. Stroke 39:831-837

4. Dani KA, McCormick MT, Muir KW (2008) Brain lesion volume and capacity for consent in stroke trials: potential regulatory barriers to the use of surrogate markers. Stroke 39:2336-2340

5. Morris MC (2005) An ethical analysis of exception from informed consent regulations. Acad Emerg Med 12:1113-1119

6. Bateman BT, Meyers PM, Schumacher HC, Mangla S, PileSpellman J (2003) Conducting stroke research with an exception from the requirement for informed consent. Stroke 34:1317-1323

7. Ali K, Roffe C, Crome P (2006) What patients want: consumer involvement in the design of a randomized controlled trial of routine oxygen supplementation after acute stroke. Stroke 37:865871

8. Blixen CE, Agich GJ (2005) Stroke patients' preferences and values about emergency research. J Med Ethics 31:608-611

9. Goldstein JN, Delaney KE, Pelletier AJ, Fisher J, Blanc PG, Halsey M, Pallin DJ, Camargo Jr CA. A Brief Educational Intervention May Increase Public Acceptance of Emergency Research without Consent. J Emerg Med. Epub before print Sept. 2008; doi:10.1016/j.jemermed.2007.12.033

10. Lecouturier J, Rodgers H, Ford GA, Rapley T, Stobbart L, Louw SJ, Murtagh MJ (2008) Clinical research without consent in adults in the emergency setting: a review of patient and public views. BMC Med Ethics 9:9 